\title{
Soft Tissue Pathology
}

Editor

ELIZABETH G. DEMICCO

\section{SURGICAL PATHOLOGY CLINICS}

www.surgpath.theclinics.com

Consulting Editor

JASON L. HORNICK

March 2019 • Volume 12 • Number 1 